\title{
Stratejik Yönetim ve İnovasyon İlişkisi: KOBİ’ler Üzerine Bir Araştırma
}

\author{
Fatih Ferhat ÇETINKAYA \\ Kırşehir Ahi Evran Üniversitesi, İ.İ.B.F., İşletme Bölümü, Kırşehir \\ ffcetinkaya@ahievran.edu.tr \\ ORCID ID: https://orcid.org/0000-0003-2263-0479 \\ Orhun GÜLBAHAR \\ Kırşehir Ahi Evran Üniversitesi, İ.İ.B.F., İşletme Bölümü Yüksek Lisans Öğrencisi, Kırşehir \\ hamdi.orhun@yahoo.com.tr \\ ORCID ID: https://orcid.org/0000-0003-3246-8305
}

\begin{tabular}{lrr} 
Araştırma Makalesi & DOI: $10.31592 /$ aeusbed.598079 \\
\hline Geliş tarihi: 29.07.2019 & Revize Tarihi: 06.11.2019 & Kabul Tarihi: 13.11 .2019
\end{tabular}

\begin{abstract}
Atıf Bilgisi
Çetinkaya, F. F. ve Gülbahar, O. (2019). Stratejik yönetim ve inovasyon ilişkisi: KOBİ'ler üzerine bir araştırma. Ahi Evran Üniversitesi Sosyal Bilimler Enstitüsü Dergisi, 5(2), 349-367.
\end{abstract}

\section{ÖZ}

Bu çalışmanın amacı, küçük ve orta büyüklükteki işletmelerde stratejik yönetim ve inovasyon arasındaki sinerjiyi yani birbirleri ile olan etkileşimi incelemektir. Nicel bir araştırma deseninde planlanan çalışmada Ankara çevresinde faaliyet gösteren 35 farklı sektördeki 300 KOBİ yöneticisiyle yüz yüze anket tekniğinden yararlanılarak veriler toplanmıştır. Toplanan veriler SPSS 23.0 ve Lisrel programlarına aktarılmış ve çözümleyici analizlere tabi tutulmuştur ve bu şekilde analizler değerlendirilmiştir. Analizlerden elde edilen sonuçlar, yapılan literatür çalışmasıyla desteklenerek KOBİ'lerde stratejik yönetim ve inovasyon arasındaki sinerji ortaya konulmuştur. Analizler sonucunda işletme yöneticilerinin stratejik yönetim algılarıyla inovasyon süreçlerine yönelik algılarının arasında anlamlı bir doğru orantı tespit edilmiştir. Ulaşılan sonuçlar doğrultusunda KOBİ'lerde stratejik yönetim ve inovasyon süreçleri arasında anlamlı bir ilişki bulunmuş ve bir takım öneriler sunulmuştur. Elde edilen veriler işletme sahipleri ile paylaşılmış ve problemlerinin çözümü konusunda katkı sağlanmaya çalışılmıştır. İşletmelerin pratikte uygulamarı ile teorik gerçekler arasında ilişki kurulmaya çalışılmıştır. Ulaşılan sonuçların ve sunulan önerilerin bu doğrultuda yapılacak çalışmalara 1şık tutacağı düşünülmektedir.

Anahtar Kelimeler: Stratejik yönetim, inovasyon, küçük ve orta büyüklükteki işletmeler.

\section{Relation of Strategic Management and Innovation: A Research on Small and Medium Sized Enterprises}

\begin{abstract}
Purpose of this research is analysing the snergy between strategic management and innovation in small and medium sized enterprises. In this quantitative study, data have collected from 300 small and medium sized enterprises which are working at 35 different industry around Ankara with the help of one-on-one survey method. Collected data have transferred into SPSS 23.0 and Lisrel programmes, so they have been subjected to analysing examinations. The snergy between strategic management and innovation in small and medium sized enterprises has revealed by the results which are supported by a literatüre research. The results have denoted the direct proportion of strategic management and innovative thinking process in business managers' perceptions. Inconsequence of results, a significant relation has discovered between strategic management and innovation process, some suggestions are indicated about study. It is tried to establish a relationship between the practical applications of enterprises and theoretical realities In the light of results and suggestions, we hope this study will be helpful for oncoming researches.
\end{abstract}

Keywords: Strategic management, innovasion, small and medium sized enterprises.

\section{Giriş}

Günümüz dünyasında küreselleşmeyle birlikte rekabetin önemi her geçen gün artmaktadır. İşletmeler ayakta kalabilmek için sürekli kendini yenilemek ve değişen koşullara ayak uydurmak zorundadırlar. Bu yenilik ve değişimleri sağlamak için işletmelerin stratejik yönetim kararları büyük önem arz etmektedir. Stratejik kararlar işletmenin geleceğini şekillendiren önemli kararlar olmakla birlikte birçok alanda alınan kararlardır. Bunlardan bir tanesi de inovasyondur. İnovasyon ve stratejik yönetim kavramları tamamen farklı kavramlar olmalarına rağmen aralarında güçlü bir ilişki vardır, çünkü inovasyon yoluyla başarılı bir değer yaratılması, işletmelerin hedefleriyle, hedefleri için belirledikleri stratejilerle, yapmış oldukları dış çevre analizleriyle, yönetim yapılarıyla, yatırımlara ayırdıkları kaynaklarla ve belirledikleri stratejiler için uyguladıkları aksiyonlarla doğrudan bağlantılıdır. 
Stratejik yönetim ve inovasyon kavramları özellikle küçük ve orta büyüklükteki işletmeler için daha fazla önem kazanmaktadır, çünkü küçük ve orta büyüklükteki işletmelerin sayısı dünyada ve ülkemizde her geçen gün artmakta ve ülkemizdeki girişimlerin \%99,8'ini küçük ve orta büyüklükteki işletmeler oluşturmaktadır. Küçük ve orta büyüklükteki işletmeler Gayrı Safi Millî Hasılaya (GSMH), istihdama, katma değer yaratmaya olan katkıları nedeniyle ülkemiz ekonomisi için hayati önem taşımaktadırlar. Günümüzün değişen dünyasında rekabetçi piyasalarda işletmelerin varlığını sürdürebilmesi ve büyüyebilmesi için stratejik yönetim bilincine sahip olmaları ve inovasyon süreçlerini başarıyla uygulayabilmeleri gerekmektedir. Bu kavramlar dünya ve ülkemiz ekonomisi açısından büyük bir öneme sahip olan KOBİ'ler için de bir zorunluluk haline gelmiştir. Küçük ve Orta Büyüklükteki İşletmelerde (KOBİ) stratejik yönetim ve inovasyon arasındaki sinerjinin araştırıldığı çalışma sayısı çok fazla olmadığından, çalışma ayrıca önem arz etmektedir. Çalışmada öncelikle stratejik yönetim ve inovasyon kavramları üzerinde durulmuş daha sonra çalışma doğrultusunda toplanan verilerin analiz sonuçları verilmiştir. Analiz sonuçları doğrultusunda bir takım önerilerde bulunulmuştur. Çalışmanın bu alanda yapılacak çalışmalara ve KOBI'lere 1şık tutacağı düşünülmektedir.

\section{Stratejik Yönetim}

Yazarlar ve dilbilimciler strateji kelimesinin kökeniyle ilgili çeşitli görüşlere sahiptirler. Kimi yazarlara göre kelime eski Yunanca'daki "stragos" (ordu) ve "'ago" (yönetmek) kelimelerinin birleşmesiyle türemişken kimi yazarlara göre ise strateji kelimesi Latince'deki "stratum" (yol, çizgi, nehir yatağı) kelimesinden türemiştir (Satı ve Işık, 2011).Sanayi devrimini izleyen yıllarda yönetim kavramı bilimsel bir konu haline gelmiştir. İlk başlarda sadece işletme içi üretim süreçlerinin verimliliğine odaklanan ve insan faktörünü göz ardı eden yönetim disiplini zamanla üretimde insan faktörü kavramını bünyesine dâhil etmiştir. Ancak bu faktörler organizasyonların iç süreçleriyle ilgilenmekte olup zamanla organizasyonların artması ve dolayısıyla rekabetin de kendini göstermesiyle yönetim disiplini aynı zamanda organizasyon dışı faktörlerle de ilgilenmek durumunda kalmıştır. Organizasyon içi faaliyetlerin ve organizasyonun dış çevre koşullarının birlikte değerlendirilmesi ihtiyacı stratejik yönetim kavramının ortaya çıkmasına neden olmuştur. Günümüzde stratejik yönetim kavramı için çeşitli tanımlamalar yapılmıştır, buna karşın net bir tanım yapmak oldukça zordur ancak özetlemek gerekirse stratejik yönetim kavramının tanımı için; Giderek artan rekabet ortamında organizasyonların üst düzey yöneticilerinin organizasyonu uzun vadede amaçlarına ulaştırmak için iç ve dış çevreyi analiz etmesi, bu doğrultuda bir takım çapraz fonksiyonel planlar geliştirmesi, geliştirdikleri planları değerlendirmesi, seçmesi, uygulaması ve ardından uygulanan planları denetlemesidir. Bu planların uygulanabilmesi için organizasyon içinde her türlü tedbirleri almak üst düzey yöneticilerin faaliyet alanına girmektedir (Peker ve Boyraz, 2017; Persaud,Woodhouse ve Scriven, 2016; Turengül, 2007).

Organizasyonlarda stratejik yönetim ve bu doğrultuda kararlar almak her ne kadar üst düzey yönetimin görev, sorumluluk ve faaliyet alanına girse de bu doğrultuda alınan kararların uygulanması ve denetimi için örgütün alt kademelerine de belirli sorumluluklar düşmektedir. Alınan kararların uygulanabilirliğini öğrenmek için gerekli bilgileri sağlamak, kararların tatbiki ve alınan kararların tatbiki sonucunda oluşan koşulları geri bildirmek alt kademelerin görev ve sorumluluğu kapsamındadır (Türk ve Kara, 2017).

Stratejik yönetimde dış çevre faktörü göz önünde bulundurularak analiz, strateji formüle etme, formüle edilen stratejilerin uygulanması ve nihayetinde uygulanan stratejilerin değerlendirilmesi süreçleri uygulanmaktadır. Bütün bu faaliyetler organizasyonların uzun dönemli faaliyetlerini önemli ölçüde etkilemektedir. (Akdemir, 2010).

Günümüz dünyasında organizasyonların sayısının artması ve küreselleşmeyle birlikte rekabet hızlı bir şekilde artmıştır. İşletmeler giderek önlerini görmekte zorlanmakta, her geçen gün rekabetin şiddeti artmakta ve boyutu çeşitlenmektedir. Bu koşullar altında işletmeler geleceklerine ilişkin öngörülerde bulunmak ve bir takım hedefler belirlemek zorundadırlar. Geleceğe dair bu öngörülerin rasyonelliği ve bu öngörüler doğrultusunda gereken tedbirlerin alınması stratejik yönetim ile mümkün olabilmektedir (Çavuş, 2005; Eşki, 2009). 


\section{Stratejik Yönetim Süreci}

Stratejik yönetimin organizasyonlarda uygulanması bir takım süreçleri zorunlu kılmaktadır. Konuyla ilgili alanyazın incelendiğinde çok sayıda araştırmacı tarafından çeşitli tanımlamalar yapıldığı görülmektedir. Bu tanımlar her araştırmacının kendi bakış açısını yansıtmakta ve tek bir tanım yapmak mümkün olmamaktadır. Ayrıca kuruluşlar stratejik yönetimle ilgili faaliyetleri geliştirmek ve yönetmek için farklı prosedürler uygulamaktadırlar. Bununla birlikte detaylardaki çeşitli farklılıklara rağmen, stratejik yönetim süreçlerinin ana hatlarının benzerlik gösterdiği görülmektedir. $\mathrm{Bu}$ ana unsurlar, stratejilerin planlanması ve geliştirilmesi, planlanan ve geliştirilen stratejilerin uygulanması ve gelişmelerin kontrol edilmesi süreçlerini kapsamaktadır (Esmaeili, 2015,).

\section{Stratejilerin Planlanması ve Geliștirilmesi}

Stratejilerin planlanması ve geliştirilmesi, bir kuruluşa gelecekteki belirli bir zaman diliminde nereye gideceğine dair talimatlar veren bir yol haritasıdır denilebilir. Stratejik plan mevcut durumdan yola çıkılarak oluşturulmalı, basit, açık, esnek ve yazılı olmalıdır. Organizasyonun bütün unsurlarını planlanan hedefler doğrultusunda birleştirmelidir. Stratejik planlama ve strateji geliştirme belirli aşamalardan oluşmaktadır. İlk aşama stratejik dizayndır. Bu aşamada kuruluşun misyonunu ve vizyonunu belirlemek gerekmektedir. Bir kurum için net bir vizyon ve misyon sahibi olmak çok önemlidir, çünkü organizasyonun nereye gittiğinden vizyon ve misyon vasıtasıyla emin olunabilir. Vizyon ve misyon belirlendikten sonra ikinci aşama gerekli analizlerin yapılması aşamasıdır. Analizler vasıtasıyla işletmenin içinde bulunduğu iç ve dış koşullar tespit edilebilmektedir. En sık kullanılan analiz yöntemleri işletme analizi, dış çevre analizi, swot analizi, portföy analizleri, delphi tekniği, q-sort analizi, nominal grup tekniği ve beş kuvvet modelidir. Gerekli analizler yapıldıktan sonra stratejilerin belirlenmesi ve seçimi aşamasına gelinmektedir. Stratejilerin belirlenmesi ve seçimi üst düzey yönetici kadrosunun yetki alanında ve sorumluluğundadır (Athapaththu, 2016; Baykal, 2018; Kılc1, 2013).

\section{Planlanan Stratejilerin Uygulanmast}

Planlanan stratejilerin uygulanması süreci stratejik planlama ve geliştirmenin bir sonraki aşamasıdır. Şirket yöneticilerini, organizasyonun departmanlarını ve çalışanlarını iç ve dış çevreyle uyumlu olmaya teşvik eden ve organizasyonun doğru gelişim yolunu gösteren kapsamlı bir yönetim eylemleri koleksiyonundan oluşmaktadır. Bu yönetim eylemleri, kaynakları kurum genelinde vizyon, misyon ve strateji ile uyumlu bir şekilde organize eder. Stratejik plan doğrultusunda gereken adımları bilerek organizasyonu hazırlar. Bunları gerçekleştirmek için grup etkinliklerini oluşturma, koordine etme, yönetme ve kontrol etme faaliyetlerini yürütür. Bütün bunları yaparken en kalifiye personelin bulunması, kullanılması, bu personelin fiziksel ve entelektüel bilgilerinin şirket hedefleriyle birleştirmek gereklidir (Athapaththu, 2016; Esmaeili, 2015).

\section{Uygulanan Stratejilerin Sonuçlarının ve Gelişmelerinin Kontrol Edilmesi}

Stratejik yönetim sürecinin son aşaması uygulanan stratejilerin kontrol evresidir. Bu aşamada uygulanan stratejilerin verimliliği ve sonuçları değerlendirilmektedir. Tepe yönetimin yürüttüğü bu süreç çeşitli değerlendirme ölçütlerinin belirlenmesiyle başlamaktadır. Daha sonra toplanan bilgilerden yola çıkarak yürütülen faaliyetlerin neler olduğu, uygulanan stratejide nasıl bir performans gösterildiği, stratejilerden sapma olup olmadığı, stratejilerin geçerliliğinin devam edip etmediği, planların geçerliliğini engelleyen faktörlerin olup olmadığı araştırılır. Bu aşamadaki amaç vizyon, misyon ve seçilip uygulanan stratejilerle elde edilen sonuçların uyumlu olup olmadığını araştırmaktır. Stratejiyle elde edilen sonuçlar arasında bir farklılık söz konusuysa alternatif stratejiler geliştirilerek plana dâhil edilmektedir (Karsavuran, 2013; Van Veen-Dirks ve Wijn, 2002).

\section{İnovasyon}

İnovasyon kelimesi Latince bir kelime olan "innovatus" kelimesinden gelmektedir. Türkçede tam bir karşıllı̆ı olmayan bu kelime yeni tekniklerin kullanılması anlamında tanımlanabilir. Formel ve 
beşeri bilimlerin pek çok alanında kullanılan bu kavram kullanıldığı alanlara göre çeşitli tanımlamalara sahiptir, fakat bu tanımlamalara bir bütün olarak bakıldı̆̆ında ortaya çıkan ortak kavram yeniliktir. İnovasyon yenilik gerektirmesine karşılık her yeniliği inovasyon olarak tanımlamak doğru değildir. Yapılan yeniliklerin inovasyon tanımına girmesi için getirdiği özgünlüğün yanında ekonomik ve sosyal anlamda bir değer yaratması gerekmektedir. İnovasyon pek çok alanda uygulanabilir bir kavramdır. İşletmeler açısından baktığımızda rekabet üstünlüğü yaratacak, nihai hedefi ekonomik bir değer üretecek olan özgün fikirler, ürünler, süreçler veya hizmetler geliştirmek olarak tanımlanabilir. Bunlar, mal, hizmet, yönetim süreçleri, pazarlama teknikleri, yeni organizasyon yapıları, yönetsel yapılar, yeni teknolojiler, fikri mülkiyet gibi alanlarda yapılabilmektedir. İşletmeler için inovasyonun amacı işletmenin amaçlarına ulaşmasına katkı sağlamak, rekabet üstünlüğü elde etmek ve tüketicileri memnun edip toplumsal fayda sağlamaktır. Günümüzün piyasa koşulları düşünüldüğünde inovasyon yapmak işletmeler açısından zorunlu bir hal almıştır, işletmeler hayatta kalmak, piyasayı kendi çıkarları doğrultusunda yönlendirip lider olabilmek için inovasyon yapmak zorundadır. Başlangıçta maliyetli gibi görünmesine karşın yapılan inovasyonlar maliyet düşürücü, kar ve verimlilik arttırıcı bir işlev görmektedirler. Bütün bunların yanında inovasyonun üretkenliği arttırdığı, yeni iş kolları yarattığı ve istihdama katkı sağladığı dolayısıyla toplumsal bir refah oluşturduğu görülmektedir (Demir ve Sezgin, 2016; Dursun, 2017; Emeksizoğlu, 2008; Keskin, 2018).

\section{İnovasyon Çeşitleri}

İnovasyonda amaç ekonomik ve sosyal bir değer yaratmak olmasına karşın inovasyon sadece üretilen yeni bir mal ve hizmet olarak görülmemelidir. İnovasyon çok çeşitli alanlarda yapılan bir takım etkinlikleri kapsamakta ve çeşitli sınıflara ayrılmaktadır. Ekonomik İşbirliği ve Kalkınma Örgütü (OECD) inovasyon türlerini; ürün inovasyonu, süreç inovasyonu, pazarlama inovasyonu ve örgütsel inovasyon olarak sıralamıştır (OECD, 2018).

\section{Ürün İnovasyonu}

Yeni icat edilmiş veya önemli ölçüde geliştirilerek yeni bir ürün halini almış ürünler üretmek ürün inovasyonu sınıfına girmektedir. Bu icat ve gelişmeler teknik özellikleri, içeriği, malzemesi, yazılımı, işlevsel özellikleri ve çevre dostu olması bakımından diğer ürünlerden önemli farklılıklar içermektedir. Ürün inovasyonunun yapılmasındaki amaç ürünlerin performansının, çeşitliliğinin geliştirilmesi ve maliyetlerin azaltılmasıdır. Böylece rekabet üstünlüğü yaratılarak pazarda belirleyici bir konuma gelinir. Ürün inovasyonu gittikçe daha fazla önem kazanmaktadır. Çünkü yeni ortaya koyulan bir ürün gittikçe daha fazla standartlaşmakta ve kullanıcılar yenilik aramaktadır. Yeni ortaya koyulan bir ürün pazarda satışları arttıracak ve karı maksimize edecektir (OECD, 2018; Utterback ve Abernathy, 1975).

\section{Süreç İnovasyonu}

Süreç inovasyonu verimliliği arttırmak ve maliyeti düşürmek amacıyla organizasyonun sisteminde yapılan bir takım değişiklikleri içerir. Bu değişiklikler fark yaratmalıdır. Yeni teknikler, ekipmanlar ve yazılımlar kullanılarak organizasyonun mevcut sisteminden bazı süreçler çıkarılabilir ya da tamamen yeni süreçler oluşturulabilir. Süreç inovasyonları, üretim veya teslimatın birim maliyetlerini düşürmek, kaliteyi artırmak, yeni veya önemli ölçüde iyileştirilmiş ürünler üretmek için tasarlanabilir (Aktaş, 2018; OECD, 2018; OECD, 2019).

\section{Pazarlama İnovasyonu}

Pazarlama inovasyonu üretilen ürünlerin tasarımında, ambalajında, konumlandırmasında, tanıtımında ve fiyatlandırmasında önemli değişikliklere gidilmesidir. Pazarlama inovasyonları, şirketin satışlarını artırmak amacıyla müşteri ihtiyaçlarını daha iyi karşılamayı, yeni pazarlar açmayı veya bir firmanın ürününü piyasada konumlandırmayı hedeflemektedir. Bir pazarlama inovasyonu bir firmanın pazarlama araçlarındaki diğer değişikliklerle karşılaştırıldığında ayırt edici özelliği, daha önce firma tarafından kullanılmayan bir pazarlama yöntemi olmasıdır. Bu yöntem mevcut pazarlama 
yöntemlerinden önemli bir farklılı̆ga sahip olmalı, yeni bir pazarlama konseptinin veya pazarlama stratejisinin bir parçası olmalıdır. Yeni pazarlama yöntemi, yenilikçi firma tarafından geliştirilebilir veya başka firmalardan veya kuruluşlardan kabul edilebilir. Hem yeni hem de mevcut ürünler için yeni pazarlama yöntemleri uygulanabilir (OECD, 2019).

\section{Örgütsel İnovasyon}

Firmanın ticari uygulamalarında, işyeri organizasyonunda veya dış ilişkilerinde yeni bir organizasyonel yöntemin uygulanmasıdır. İşyeri organizasyonunda yenilikler yapmak, çalışanlar arasında, firma faaliyetleri içinde ve arasında iş bölümü oluşturmak, sorumlulukların ve karar yetkilerinin çalışanlara daha fazla dağıtılması ayrıca farklı iş faaliyetlerinin entegrasyonu gibi faaliyetlerin yapılandırılması için yeni süreçlerin uygulanmasını içerir. Örneğin işyeri organizasyonunda firma çalışanlarına karar vermede daha fazla özerklik veren ve fikirlerini sunarak örgüte katkıda bulunmalarını teşvik eden bir örgütsel modelin organizasyon içinde ilk defa uygulanması bir örgütsel inovasyon örneğidir. Örgütsel inovasyon, faaliyetsel ve yönetimsel maliyetleri azaltır, işletmenin performansını arttırmayı amaçlar. Mevcut iş modelleri firma şartlarına uyarlanılarak ya da yeni metodlar geliştirilerek örgütsel inovasyon yapılmaktadır (OECD, 2019; Öztokmak, 2018).

\section{Araştırmanın Modeli}

\section{Yöntem}

$\mathrm{Bu}$ araştırmanın amacı stratejik yönetim olgusunun inovasyon süreçleri üzerindeki etkisini incelemektir. Bu doğrultuda araştırma nicel araştırma yöntemlerinden genel tarama modelinden ilişkisel tarama modelinde desenlenmiştir. Genel tarama modeli araştırmaya dâhil olan örneklemin özelliklerinin sayısal bir şekilde betimlenmesidir (Creswell, 2009). İlişkisel tarama modelinde de bir grubun düşünceleri, tutumları veya eğilimleri arasında korelasyonlar hesaplanarak ilişkiler saptanmaktadır; bu doğrultuda araştırma korelasyonel araştırma olarak da adlandırılmaktadır( Büyüköztürk, Çakmak, Akgün, Karadeniz ve Demirel, 2010).

\section{Çalışma Grubu}

Araştırmanın evrenini Ankara ilinde faaliyet gösteren Küçük ve Orta Büyüklükteki İşletmelerin (KOBİ) yöneticileri oluşturmaktadır. Ankara ilinde yaklaşık $150.000 \mathrm{KOBİ} \mathrm{olduğu} \mathrm{ilgili} \mathrm{kurumlardan}$ belirlenmiştir (Ankara Ticaret Odası). Araştırma kapsamında boya malzemeleri, cam, çimento, mobilya, otomotiv gibi 35 farklı alanda faaliyet gösteren iş yerlerinde görev yapmakta olan toplam 300 yönetici ile görüşülmüştür. Bunun ardından Büyüköztürk ve arkadaşlarının (2014) farklı sapma adetleri için uygun örneklem büyüklüklerine göre yapılan hesaplamada 275 ve üzeri örneklem büyüklügünün çalışma için uygun olacağı saptanmıştır. Araştırma kapsamında amaçlı örnekleme yöntemlerinden maksimum çeşitlilik örnekleme yöntemi kullanılarak farklı faaliyet alanlarından, işletme büyüklüklerinden, 1963-2018 yılları arasında kurulmuş iş yerlerinin yöneticileri çalışmaya dâhil edilmiştir. Yöneticilerin ve iş yerlerinin özelliklerine göre dağılımlarına ilişkin frekans ve yüzde değerleri hesaplanmış, sonuçlar Tablol'de gösterilmiştir.

Tablo 1

Yöneticilerin ve Görev Yaptıkları İş Yerlerinin Bazı Özelliklerine Göre Dağıllımı

\begin{tabular}{|c|c|c|c|}
\hline Değișkenler & Kategoriler & $\mathrm{f}$ & $\%$ \\
\hline \multirow[t]{4}{*}{ Çalışan sayısı } & $1-9$ & 91 & 30.3 \\
\hline & $10-49$ & 114 & 38.0 \\
\hline & $50-249$ & 68 & 22.7 \\
\hline & 250 ve üstü & 27 & 9.0 \\
\hline \multirow[t]{3}{*}{ Yönetim yapıs1 } & Aile bireyleri & 206 & 68.7 \\
\hline & Aile dişından ortaklar & 66 & 22.0 \\
\hline & Profesyonel yöneticiler & 28 & 9.3 \\
\hline \multirow[t]{3}{*}{ Y1llik ciro } & 1 milyon TL'den az & 116 & 38.7 \\
\hline & 1-4 milyon TL & 71 & 23.7 \\
\hline & 5-25 milyon $\mathrm{TL}$ & 46 & 15.3 \\
\hline
\end{tabular}




\begin{tabular}{llrr}
\hline & 25 milyon TL'den fazla & 67 & 22.3 \\
Yönetici olarak çalışma süresi & 1 yıldan az & 68 & 22.7 \\
& $1-3$ yıl & 45 & 15.0 \\
& $4-6$ yıl & 33 & 11.0 \\
& $7-9$ yıl & 25 & 8.3 \\
& 10 yıl ve üzeri & 129 & 43.0 \\
\hline
\end{tabular}

Tablo 1'de yer alan bilgiler incelendiğinde, çalışmaya katılan kişilerin \%30,3'ünün ( $n=91)$ mikro ölçekli ișletmelerde, \%38,0'inin (n=114) küçük ölçekli işletmelerde, \%22,7'sinin $(n=68)$ orta ölçekli işletmelerde, $\% 9,0$ 'unun da $(\mathrm{n}=27)$ büyük ölçekli işletmelerde yöneticilik yaptığı görülmektedir. Araştırma kapsamında görüşleri alınan kişilerden \%68,7'sinin $(\mathrm{n}=206)$ aile bireylerinden oluşan şirkette, \%22,0'sinin ( $\mathrm{n}=66)$ aile dişından ortaklarla oluşan şirkette yönetici olduğu, \%9,3'ünün (n=28) ise profesyonel yöneticilerden oluşan şirkette yönetici olarak görev yaptığ1 tespit edilmiştir. Yöneticilerden \%38,7'si ( $\mathrm{n}=116)$ y1llık cirosu bir milyon TL'den az işletmelerde, \%23,7'si (n=71) 1-4 milyon TL arasında olan işletmelerde, \%15,3'ü $(\mathrm{n}=46)$ 5-25 milyon TL arasında olan işletmelerde, \%22,3'ü (n=67) yıllık cirosu 25 milyon TL'den fazla olan işletmelerde çalışmaktadır. Araştırmaya katılan yöneticilerden \%22,7'sinin $(n=68) 1$ yıldan daha az süredir, \%15,0'inin $(n=45) 1-3$ yıldır, \%11,0'inin (n=33) 4-6 yıldır, \%8,3'ünün $(n=25)$ 7-9 yıldır, \%43,0'ünün $(n=129) 10$ yıl ve üzeri bir süredir yöneticilik yaptığı belirlenmiştir.

\section{Veri Toplama Araçları}

$\mathrm{Bu}$ çalışma nicel araştırma deseninde planlanmış ve çalışmanın verilerini toplamak amacıyla anket tekniğinden faydalanılmıştır. Ölçme aracı olarak; "İşletmelerdeki İnovasyon Uygulamaları Ölçeği ve Stratejik Yönetim Ölçeği kullanılmıştır. Ayrıca ölçme aracında sosyo-demografik bilgileri elde etmek amacıyla sorular bulunmaktadır. Ölçme aracı olarak Kılıç ve Keklik (2012) tarafından geliştirilen "İnovasyon Süreçleri Ölçeği" kullanılmıştır. 5'li likert tipi bulunan ölçekte 17 ifade yer almaktadır. Yapılan analiz neticesinde "İnovasyon Süreçleri Ölçeğinin" Cronbach alfa katsayısının 0,86 olduğu tespit edilmiş ve ölçeğin güvenilir olduğu sonucuna ulaşılmıştır. Diğer ölçme aracı olarak ise Demir (2017) tarafından geliştirilen "Stratejik Yönetim Ölçeği" kullanılmıştır. Bu ölçme aracında ise yine 5'li likert yapısı bulunmakta olup, 10 soru yer almaktadır. "Stratejik Yönetim Ölçeğinin" güvenirlik düzeyini belirlemek amacıyla yapılan analizde Cronbach alfa katsayısı hesaplanmış ve 0,91 olarak bulunmuştur. Akgül ve Çevik'e (2003) göre 0,80 ile 1,00 değer aralığındaki alfa katsayısı yüksek derecede güvenilir bir ölçek olduğunun göstergesidir.

\section{Verilerin Analizi}

Verilerin analizi sürecinde öncelikle yöneticilerden elde edilen cevaplar SPSS 23.0 ve Lisrel programlarına aktarılmıştır. Ardından eksik veri olup olmadığının belirlenmesi için maddeler bazında frekans değerleri hesaplanmıştır. Ardından hatalı veri girişi incelemesine yönelik en düşük-en yüksek değer incelemesi yapılmıştır. Veri seti kontrol edildikten sonra alt boyutlar ve ölçeğin tamamına ilişkin toplam puanlar hesaplanmıştır. Toplam puanlarda uç değer olup olmadığının tespit edilmesi amacıyla z istatistiğinden yararlanılmıştır. Hesaplama sonucunda $\mathrm{z}$ istatistiğinin tüm puanlarda \pm 3 arasında değer aldığı, başka bir anlatımla veri setinde uç değer özelliği gösteren veri olmadığı, belirlenmiştir. Veri setinin büyük olması durumunda normallik testleri yanıltıcı sonuçlar verebileceğinden (Çokluk, Şekercioğlu ve Büyüköztürk, 2010) araştırmaya katılan 300 yöneticinin görüşlerinin dağ 1 lımına ilişkin çarpıklık ve basıklık katsayıları hesaplanmıştır. Hesaplanan değerlerin \pm 1 arasında yer aldığı, diğer bir anlatımla veri setlerinin dağılımının normallikten aşırı bir sapma göstermediği tespit edilmiştir. Normallik incelemesine yönelik ayrıca histogram grafiklerinden yararlanılmıştır. Oluşturulan grafikler aşağıda gösterilmiştir. 


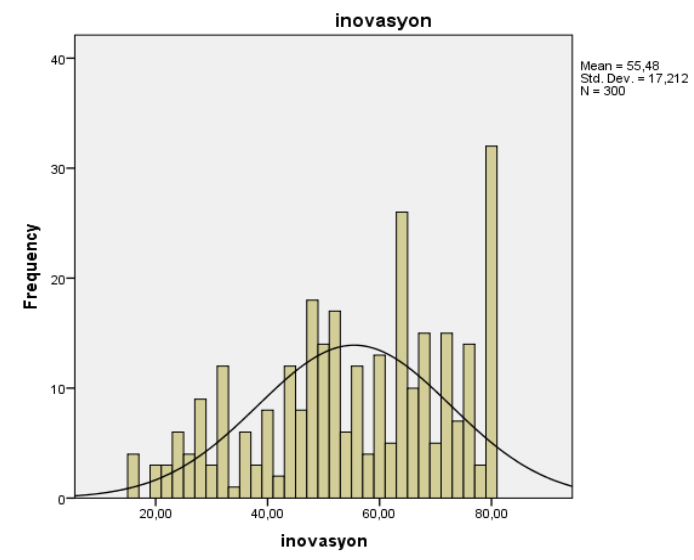

Grafik 1:Puanların Dağılımına İlişkin Oluşturulan Histogram Grafikleri

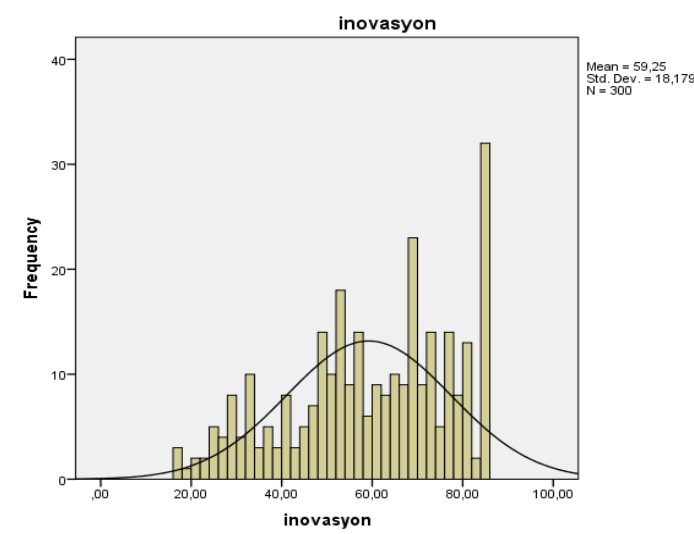

Grafik 2: Puanların Dağılımına İlişkin Oluşturulan Histogram Grafikleri

Yöneticilerin inovasyon süreçleri alt boyutları ve toplam puanları ile stratejik yönetimleri arasındaki ilişkilerin 0,90 'dan daha düşük olduğu belirlenmiştir. Diğer bir ifadeyle veri setinde çoklu bağlantı problemi olmadığı tespit edilmiştir. Hesaplanan Durbin Watson değeri de 1,740 olarak bulunmuştur. Söz konusu değerin 1,5-2,5 arasında değer alması durumunda veri setinde oto-korelasyon olmadığı belirlenmektedir. Tüm bu incelemeler doğrultusunda yöneticilerden elde edilen veri setinin çok değişkenli bir istatistik olan yapısal eşitlik modellemesinin varsayımlarını karşıladığı sonucuna ulaşılmaktadır.

Yöneticilerin stratejik yönetim ve inovasyon süreçleri arasındaki ilişkilerin belirlenmesi amacıyla Pearson korelasyon katsayısı hesaplanmıştır. Stratejik yönetim kararlarının inovasyon üzerindeki etkisini belirlemek amacıyla da Yapısal Eşitlik Modellemesi (YEM) yapılmıştır.

\section{Bulgular}

\section{Yöneticilerin Stratejik Yönetim Algılarının Düzeylerinin Belirlenmesi}

Araştırma kapsamında görüşleri alınan yöneticilerin stratejik yönetim algı düzeylerini belirlemek amaciyla uygulanan ölçek maddelerine vermiş oldukları cevaplar doğrultusunda betimsel istatistikler hesaplanmış, sonuçlar Tablo 2'de gösterilmiştir. 
Tablo 2

Yöneticilerin Stratejik Yönetim Algı Düzeylerine İlişkin Hesaplanan Betimsel İstatistikler

\begin{tabular}{lrrrrr}
\hline Ölçek & $\mathrm{N}$ & En düşük & En yüksek & $\bar{X}$ & $\mathrm{SS}$ \\
\hline Stratejik yönetim ölçeği & 300 & 10,00 & 50,00 & 32.45 & 11.09 \\
\hline
\end{tabular}

Tablo 2'de yer alan bilgiler incelendiğinde araştırma kapsamında görüşleri alınan yöneticilerin stratejik yönetim puanlarının 10,00 ile 50,00 arasında değişiklik gösterdiği tespit edilmiştir.

Yöneticilerin stratejik yönetim puanlarının ortalaması 32,45 $( \pm 11,09)$ olarak hesaplanmıștır. Bu doğrultuda araştırmaya katılan yöneticilerin stratejik yönetimlerinin genel olarak orta düzeyde olduğu görülmektedir.

\section{Yöneticilerin İnovasyon Süreçlerine Yönelik Algılarının Belirlenmesi}

Araştırmaya katılan yöneticilerin inovasyon süreçlerine yönelik algılarını belirlemek amacıyla katılımcıların ölçek maddelerine vermiş oldukları cevaplar doğrultusunda betimsel istatistikler hesaplanmış, sonuçlar Tablo 3'te gösterilmiştir.

Tablo 3

Yöneticilerin İnovasyon Süreçlerine İlişkin Hesaplanan Betimsel İstatistikler

\begin{tabular}{lrrrrr}
\hline Ölçek boyutları & $\mathrm{N}$ & En düşük & En yüksek & $\bar{X}$ & SS \\
\hline Ürün inovasyonu & 300 & 6.00 & 30.00 & 16.44 & 7.93 \\
Süreç inovasyonu & 300 & 5.00 & 25.00 & 19.80 & 5.87 \\
Pazar inovasyonu & 300 & 3.00 & 15.00 & 11.47 & 4.58 \\
Örgütsel inovasyon & 300 & 3.00 & 15.00 & 11.53 & 3.81 \\
İnovasyon (toplam) & 300 & 17.00 & 85.00 & 59.25 & 18.18 \\
\hline
\end{tabular}

Tablo 3'te ki bilgiler incelendiğinde yöneticilerin ürün inovasyonuna yönelik puanlarının 6,00 ile 30,00 arasında değişiklik göstermektedir, ortalaması 16,44 $( \pm 7,93)$ olarak hesaplanmıştır. Yöneticilerin süreç inovasyonuna ilişkin puanları 5,00 ile 25,00 arasında değişmektedir, ortalaması $19,80( \pm 5,87)$ 'dir. Yöneticilerin pazar inovasyonuna ilişkin puanları 3,00 ile 15,00 arasında farklılık göstermektedir, ortalaması $11,47( \pm 4,58)$ olarak hesaplanmıştır. Araştırmaya katılan yöneticilerin örgütselinovasyon puanları 3,00 ile 15,00 arasında farklılık göstermekte, ortalamas1 11,53 $( \pm 3,81)$ olarak hesaplanmıştır. Araştırma kapsamında görüşleri alınan yöneticilerin inovasyon süreçlerine yönelik puanlarının 17,00 ile 85,00 arasında farklılık gösterdiği, ortalamasının da 59,25 $( \pm 18,18)$ olarak olduğu tespit edilmiştir.

İnovasyon süreçleri ölçeğindeki boyutlarda yer alan madde sayıları farklıdır. Bu nedenle karşılaştırma kolaylığı açısından her bir boyutun ortalama değeri boyutta yer alan madde sayısına bölünerek 1-5 ranjına getirilmiştir. Sonuçlar Tablo 4’te gösterilmiş̧ir.

Tablo 4

Yöneticilerin İnovasyon Süreçlerine İlişkin Madde Bazında Hesaplanan Betimsel İstatistikler

\begin{tabular}{lcccc}
\hline Ölçek boyutları & $\mathrm{N}$ & $\bar{X}$ & Madde sayısı & \multicolumn{2}{c}{ Madde } \\
\hline Ürün inovasyonu & & & 6 & 2.7 \\
Süreç inovasyonu & 300 & 16.44 & 5 & 4.0 \\
\hline
\end{tabular}




\begin{tabular}{lcccc}
\hline Pazar inovasyonu & 300 & 11.47 & 3 & 3.8 \\
Örgütsel inovasyon & 300 & 11.53 & 3 & 3.8 \\
İnovasyon (toplam) & 300 & 59.25 & 17 & 3.5 \\
\hline
\end{tabular}

Tablo 4'te araştırmaya katılan yöneticilerin en çok süreç inovasyonu algılarının, daha sonra pazar ve örgütsel inovasyon algılarının yüksek olduğu görülmektedir. Araştırmaya katılan yöneticilerin inovasyon süreçlerine ilişkin en düşük ortalamanın ürün inovasyonu boyutuna ait olduğu belirlenmiştir. Yöneticilerin genel olarak inovasyon süreçlerinin de orta düzeyde olduğu tespit edilmiştir.

\section{Yöneticilerin Stratejik Yönetim Algıları İle İnovasyon Süreçleri Arasındaki İlişki}

Araştırmaya katılan yöneticilerin stratejik yönetim algıları ile inovasyon süreçleri arasındaki ilişkilerin tespit edilmesi amacıyla Pearson korelasyon katsayısı hesaplanmıştır. Sonuçlar Tablo 5'te gösterilmiştir.

Tablo 5

Yöneticilerin Stratejik Yönetim Algıları İle İnovasyon Süreçleri Arasındaki İlişkilere Yönelik Hesaplanan Korelasyon Katsayısı Sonuçları

\begin{tabular}{|c|c|c|c|c|c|c|c|}
\hline Ölçekler & Değerler & $\begin{array}{l}\text { Stratejik } \\
\text { yönetim }\end{array}$ & $\begin{array}{c}\text { Ürün } \\
\text { inovasyonu }\end{array}$ & $\begin{array}{c}\text { Süreç } \\
\text { inovasyonu }\end{array}$ & $\begin{array}{c}\text { Pazar } \\
\text { inovasyonu }\end{array}$ & $\begin{array}{c}\text { Organizasyonel } \\
\text { inovasyon }\end{array}$ & $\begin{array}{c}\text { İnovasyon } \\
\text { (toplam) }\end{array}$ \\
\hline \multirow{3}{*}{ Stratejik yönetim } & $\mathrm{r}$ & 1 & $.676^{* *}$ & $.646^{\text {** }}$ & $.588^{* *}$ & $.618^{* *}$ & $.780^{* *}$ \\
\hline & $\mathrm{p}$ & & .000 & .000 & .000 & .000 & .000 \\
\hline & $\mathrm{N}$ & 300 & 300 & 300 & 300 & 300 & 300 \\
\hline \multirow{3}{*}{ Ürün inovasyonu } & $\mathrm{r}$ & $.676^{* *}$ & 1 & $.531^{* *}$ & $.450^{* *}$ & $.446^{* *}$ & $.814^{* *}$ \\
\hline & $\mathrm{p}$ & .000 & & .000 & .000 & .000 & .000 \\
\hline & $\mathrm{N}$ & 300 & 300 & 300 & 300 & 300 & 300 \\
\hline \multirow{3}{*}{ Süreç inovasyonu } & $\mathrm{r}$ & $.646^{* *}$ & $.531^{* *}$ & 1 & $.664^{* *}$ & $.656^{* *}$ & $.859^{* *}$ \\
\hline & $\mathrm{p}$ & .000 & .000 & & .000 & .000 & .000 \\
\hline & $\mathrm{N}$ & 300 & 300 & 300 & 300 & 300 & 300 \\
\hline \multirow{3}{*}{ Pazar inovasyonu } & $\mathrm{r}$ & $.588^{* *}$ & $.450^{* *}$ & $.664^{* * *}$ & 1 & $.687^{* *}$ & $.806^{* *}$ \\
\hline & $\mathrm{p}$ & .000 & .000 & .000 & & .000 & .000 \\
\hline & $\mathrm{N}$ & 300 & 300 & 300 & 300 & 300 & 300 \\
\hline \multirow{3}{*}{ Örgütselinovasyon } & $\mathrm{r}$ & $.618^{* *}$ & $.446^{* *}$ & $.656^{* *}$ & $.687^{* *}$ & 1 & $.788^{* *}$ \\
\hline & $\mathrm{p}$ & .000 & .000 & .000 & .000 & & .000 \\
\hline & $\mathrm{N}$ & 300 & 300 & 300 & 300 & 300 & 300 \\
\hline \multirow{3}{*}{ İnovasyon (toplam) } & $\mathrm{r}$ & $.780^{* *}$ & $.814^{* * *}$ & $.859^{* *}$ & $.806^{* *}$ & $.788^{* *}$ & 1 \\
\hline & $\mathrm{p}$ & .000 & .000 & .000 & .000 & .000 & \\
\hline & $\mathrm{N}$ & 300 & 300 & 300 & 300 & 300 & 300 \\
\hline
\end{tabular}

$* \mathrm{p}<0,05 ; * * \mathrm{p}<0,01$

Tablo 5 'te ki bilgiler incelendiğinde yöneticilerin stratejik yönetim algıları ile ürün inovasyonu $(\mathrm{r}=0,676 ; \mathrm{p}<0,01)$, süreç inovasyonu $(\mathrm{r}=0,646 ; \mathrm{p}<0,01)$, pazar inovasyonu( $\mathrm{r}=0,588 ; \mathrm{p}<0,01)$, örgütsel inovasyon $(\mathrm{r}=0,618 ; \mathrm{p}<0,01)$ ve genel olarak inovasyon süreçleri $(\mathrm{r}=0,780 ; \mathrm{p}<0,01)$ arasında pozitif yönde, orta ve yüksek düzeyde ilişkiler olduğu görülmektedir.

İnovasyon süreçlerinin kendi alt boyutları arasındaki ilişkilerin de pozitif ve yüksek düzeyde olduğu; inovasyon süreçlerine yönelik en yüksek ilişkinin süreç inovasyonu ile olduğu belirlenmiştir $(\mathrm{r}=0,859 ; \mathrm{p}<0,01)$.

\section{Yöneticilerin İnovasyon Süreçleri ve Stratejik Yönetim Algıları}

Araştırmaya katılan yöneticilerin inovasyon süreçlerinin stratejik yönetim algıları tarafindan ne düzeyde açıklandığının belirlenmesi amaçlanmıştır. İnovasyon süreçleri ürün inovasyonu, süreç inovasyonu, pazar inovasyonu ve örgütsel inovasyon olmak üzere dört alt boyutta oluşmaktadır. 
Stratejik yönetim algısının inovasyon süreçlerini ne derece açıkladığına yönelik yapısal eşitlik modellemesi kurulmuştur. Yapısal eşitlik modellemesi (YEM), sürekli ya da kategorik olan bir ya da daha fazla bağımsız değişken ile yine sürekli ya da kategorik olabilen bir ya da daha fazla bağımlı değişken arasındaki ilişkileri açıklayan istatistiksel teknikler bütünüdür (Tabachnic ve Fidell, 2017). Araştırmada birden fazla gizil değişken ve onlara ilişkin göstergeler (maddeler) bulunduğu için birden çok regresyon analizinin aynı anda yapıldığı hibrid bir model kurulmuştur. Model sonrasında oluşturulan path diyagramı Şekil 2'de gösterilmiştir.

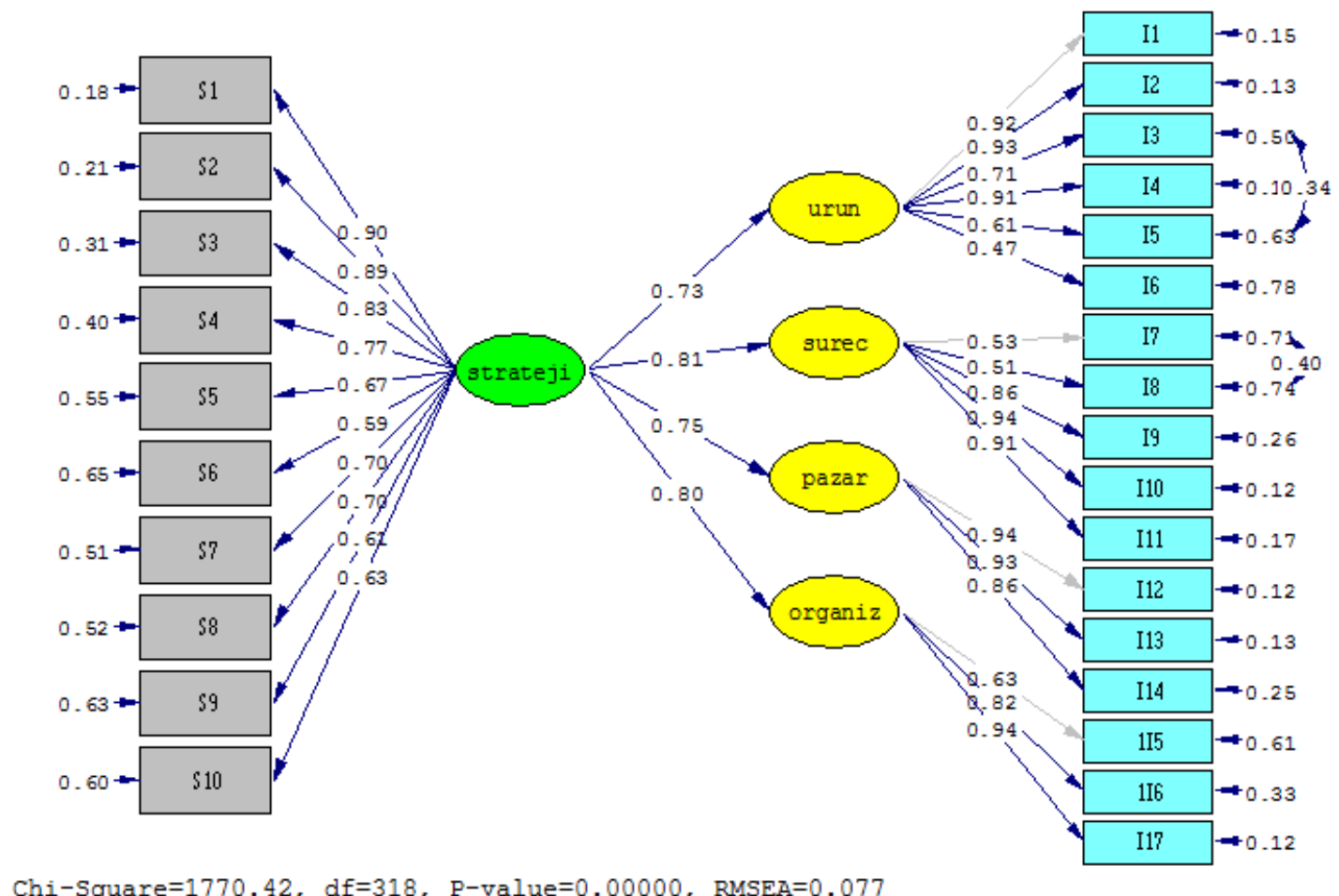

Grafik 3: Yöneticilerin Stratejik Yönetim Algılarının Açıklanmasına Yönelik Oluşturulan Path Diyagramı-Standartlaştırılmış Katsayılar

Model betimlendikten ve tanımlandıktan sonra modelin hesaplama aşamasına geçilmiştir. $\mathrm{Bu}$ süreçte değişkenlere ilişkin faktör yük değerleri, standartlaştırılmış regresyon katsayıları ve t değerleri hesaplanmıştır. Standartlaştırılmış faktör yükleri ( $\lambda=$ Lambda), gizil değişkendeki bir birim değişikliğin, gözlenen değişkende ne kadar değişkenliğe yol açacağı başka bir deyişle gözlenen değişken ile ilgili gizil değişken arasındaki ilişki konusunda fikir vermektedir. Bu değerlerin yüksek olması gizil ve gözlenen değişken arasında güçlü bir ilişki olduğunu göstermektedir. Standartlaştırılmış regresyon katsayıları (R2) değerleri, gözlenen değişkendeki açıklanan varyansın ne kadarının gizil değişkenden kaynaklandığını göstermektedir (Çokluk ve diğerleri, 2010). Sonuçlar Tablo 6'da gösterilmiştir.

Tablo 6

Yöneticilerin Stratejik Yönetim Ölçeğine Vermiş Oldukları Cevaplara İlişkin Hesaplanan Değerler

\begin{tabular}{|c|c|c|c|}
\hline Maddeler & Standartlaştırılmış Faktör Yükleri $(\lambda)$ & Regresyon değerleri $\left(\mathrm{R}^{2}\right)$ & $t$ değeri \\
\hline S1 & 0.90 & 0.82 & 10.15 \\
\hline S2 & 0.89 & 0.79 & 19.51 \\
\hline S3 & 0.83 & 0.69 & 17.44 \\
\hline S4 & 0.77 & 0.60 & 15.68 \\
\hline S5 & 0.67 & 0.45 & 12.89 \\
\hline S6 & 0.59 & 0.35 & 10.97 \\
\hline S7 & 0.70 & 0.49 & 13.70 \\
\hline S8 & 0.70 & 0.48 & 13.59 \\
\hline S9 & 0.61 & 0.37 & 11.49 \\
\hline S10 & 0.63 & 0.40 & 12.07 \\
\hline
\end{tabular}


Tablo 6' da yer alan bilgiler incelendiğinde yöneticilerin stratejik yönetim algılarını belirlemek üzere oluşturulan maddelerin standartlaştırılmış faktör yük değerleri 0,59 ile 0,90 arasında değişiklik göstermektedir. Standartlaştırılmış regresyon katsayıları da 0,35 ile 0,82 arasında farklılık göstermektedir. Tüm maddelerin t değerlerinin anlamlı olduğu belirlenmiştir. Diğer bir ifadeyle stratejik yönetim ölçeğinde yer alan maddelerin yöneticilerin stratejik yönetim algılarını orta ve yüksek düzeyde açıkladığı görülmektedir. Yöneticilerin inovasyon süreçlerine yönelik hesaplanan değerler Tablo 7'de gösterilmiştir.

Tablo 7

Yöneticilerin İnovasyon Süreçleri Ölçeğine Vermiş Oldukları Cevaplara İlişkin Hesaplanan Değerler

\begin{tabular}{|c|c|c|c|c|}
\hline Ölçek boyutları & Maddeler & $\begin{array}{r}\text { Standartlaştırılmış Faktör Yükleri } \\
(\lambda)\end{array}$ & $\begin{array}{r}\text { Regresyon değerleri } \\
\left(\mathrm{R}^{2}\right)\end{array}$ & t değeri \\
\hline \multirow{7}{*}{ Ürün inovasyonu } & I1 & 0.92 & 0.85 & --- \\
\hline & I2 & 0.93 & 0.87 & 28.35 \\
\hline & I3 & 0.71 & 0.50 & 15.58 \\
\hline & I4 & 0.91 & 0.83 & 26.76 \\
\hline & I5 & 0.61 & 0.37 & 12.19 \\
\hline & I6 & 0.47 & 0.22 & 8.74 \\
\hline & I7 & 0.53 & 0.29 & -- \\
\hline \multirow[t]{5}{*}{ Süreç inovasyonu } & I8 & 0.51 & 0.26 & 10.88 \\
\hline & I9 & 0.86 & 0.74 & 9.93 \\
\hline & I10 & 0.94 & 0.88 & 10.31 \\
\hline & I11 & 0.91 & 0.83 & 10.18 \\
\hline & I12 & 0.94 & 0.88 & --- \\
\hline \multirow[t]{3}{*}{ Pazar inovasyonu } & I13 & 0.93 & 0.87 & 28.93 \\
\hline & I14 & 0.86 & 0.75 & 23.78 \\
\hline & I15 & 0.63 & 0.39 & -- \\
\hline \multirow[t]{2}{*}{ Örgütselinovasyon } & I16 & 0.82 & 0.67 & 11.50 \\
\hline & I17 & 0.94 & 0.88 & 12.22 \\
\hline
\end{tabular}

Tablo 7'de görüldüğü gibi yöneticilerin cevapları doğrultusunda ürün inovasyon süreçlerine yönelik maddelerin faktör yük değerlerinin 0,47 ile 0,93 arasında değiștiği, regresyon katsayılarının da 0,22 ile 0,87 arasında farklılık gösterdiği görülmektedir. Benzer şekilde süreç inovasyonunu ölçmeyi amaçlayan maddelerin faktör yük değerlerinin 0,51 ile 0,94 arasında değiştiği, standartlaştırılmış regresyon katsayısının 0,26 ile 0,88 arasında farklılaştığı tespit edilmiştir. Pazar inovasyonuna ilişkin maddelerin faktör yük değerlerinin 0,86 ile 0,94 arasında farklılaştığı, standartlaştırılmış regresyon katsayılarının da 0,75 ile 0,88 arasında değiştiği belirlenmiştir. Örgütsel inovasyon süreçlerindeki maddelerin faktör yük değerlerinin 0,63 ile 0,94 arasında değiştiği, regresyon katsayılarının da 0,39 ile 0,88 arasında farklılaştığı tespit edilmiştir. İnovasyon süreçleri ölçeğindeki tüm maddelerin $\mathrm{t}$ değerlerinin anlamlı olduğu belirlenmiştir. Ölçekte yer alan maddelerin orta ve yüksek düzeyde açıklayıc1lığa sahip olduğu sonucuna ulaşılmıştır.

Ölçme eşitliklerinde modelden çıkarılması gereken madde olmadığı belirlenmiş, ardından yapısal eşitlikler incelenmiştir. Yapısal eşitlikler bağlamında hesaplanan katsayılar Tablo 8'de gösterilmiştir.

Tablo 8

Yöneticilerin Stratejik Yönetimlerinin Açıklanmasına Yönelik Kurulan Yapısal Eșittikler

\begin{tabular}{lrrrr}
\hline Alt boyutlar & Açılanan değişken & $\mathrm{R}^{2}$ & $\beta$ & $\mathrm{t}$ \\
\hline Ürün inovasyonu & & 0.73 & 0.53 & 13.36 \\
Süreç inovasyonu & & 0.78 & 0.66 & 8.95 \\
Pazar inovasyonu & Stratejik yönetim & 0.75 & 0.56 & 13.92 \\
Örgütselinovasyon & & 0.80 & 0.64 & 10.12 \\
\hline
\end{tabular}

Tablo 8'de yer alan bilgiler incelendiğinde, araştırmaya katılan yöneticilerin stratejik yönetim algılarının inovasyon süreçleri içerisinde en çok örgütselinovasyon süreçleri tarafından açıklandığı belirlenmiştir $(R 2=0,80 ; p<0,05)$. Ardından yöneticilerin süreç inovasyonu ( $R 2=0,78 ; p<0,05)$, pazar 
inovasyonu ( $R 2=0,75 ; \mathrm{p}<0,05)$ ve ürün inovasyonu $(\mathrm{R} 2=0,73 ; \mathrm{p}<0,05)$ tarafından stratejik yönetim algılarının açıklandığı tespit edilmiştir. Beta katsayılarının pozitif ve yüksek düzeyde hesaplanması, yöneticileri inovasyon süreçleri artış gösterdikçe stratejik yönetimlerinin artış gösterdiğini ifade etmektedir.

Yöneticilerin stratejik yönetimlerinin açıklanmasına ilişkin kurulan modelin hesaplama aşamasından sonra model-veri uyum indeksleri değerlendirilmiştir.

Tablo 9

Yöneticilerin Stratejik Yönetimlerinin Açıklanmasına Yönelik Oluşturulan Modele İlişkin Hesaplanan Model-Veri Uyum Indeksleri

\begin{tabular}{lccr}
\hline Uyum Ölçütleri & Mükemmel Uyum & Kabul Edilebilir Uyum & Model değerleri \\
$\mathrm{X}^{2} / \mathrm{sd}$ & $0 \leq \mathrm{X}^{2} / \mathrm{sd} \leq 4$ & $0 \leq \mathrm{X}^{2} / \mathrm{sd} \leq 5$ & 5.57 \\
RMSEA & $0 \leq \mathrm{RMSEA} \leq .05$ & $.05<\mathrm{RMSEA} \leq .08$ & 0.077 \\
$\mathrm{NFI}$ & $.95 \leq \mathrm{NFI} \leq 1.00$ & $.90 \leq \mathrm{NFI}<.95$ & 0.92 \\
$\mathrm{NNFI}$ & $.97 \leq \mathrm{NNFI} \leq 1.00$ & $.95 \leq \mathrm{NNFI}<.97$ & 0.92 \\
$\mathrm{CFI}$ & $.95 \leq \mathrm{CFI} \leq 1.00$ & $.90 \leq \mathrm{CFI}<.95$ & 0.93 \\
$\mathrm{IFI}$ & $.95 \leq \mathrm{IFI} \leq 1.00$ & $.90 \leq \mathrm{IFI}<.95$ & 0.93 \\
\hline
\end{tabular}

Tablo 9'daki model-veri uyum değerleri incelendiğinde yöneticilerin stratejik yönetim algılarının oluşturulmasına yönelik oluşturulan modelin veri uyumunu sağladığı belirlenmiştir. Diğer bir anlatımla araştırmaya katılan yöneticilerin verilerinin oluşturulan modeli doğruladığı tespit edilmiştir.

\section{Sonuç, Tartışma ve Öneriler}

Konuyla ilgili ulusal alan yazın incelendiğinde Satı ve Işık (2011) çalışmalarında işletmenin inovasyon başarısını ekonomik ve entelektüel sermayesinin yanı sıra örgütün bunları yönetebilme becerilerine de bağlı olduğunu savunmuştur. İşletmelerin yönetim becerileri ise uzun vadeli bakış açısı, pazar analizi, bilgileri toplama, işleme ve özümseme yeteneği gibi stratejik yönetim kavramlarıla gerçekleşmektedir. İşletme içi inovasyon politikaları stratejilerle desteklenmeli ve bu sayede işletmeler varlıklarını hızla gelişen piyasa koşullarında devam ettirebilmektedirler. Demir ve Sezgin (2016) çalışmalarında KOBİ'lerin ülke ekonomisi için çok önemli bir unsur olduğunu buna karşın günümüzün gerektirdiği değişimlere hızlı bir şekilde adapte olamadıklarını belirtmişlerdir. Günümüzde KOBİ'lerin hızla değişen şartlara adapte olarak başarılı olma koşulunu ise stratejik yönetim modellerini uygulamalarına ve inovasyon politikalarını hayata geçirmelerine bağlı olduğunu dile getirmişlerdir. Hancıoğlu ve Yeşilaydın (2016) çalışmalarında rekabet koşulları karşısında işletmenin sürekliliği için inovasyonu temel zorunluluklardan biri olarak kabul etmiş, işletmelerin inovasyona dayalı faaliyetlerde bulunmasının örgütsel yapılanmalarda dönüşüme gidilmesine bağlı olduğunu belirtmişlerdir. $\mathrm{Bu}$ dönüşümler stratejik yönetim kararlarını gerçekleştiren dönüşümlerdir. Kalay, Tuncer, Kızıldere ve Kalay (2015) çalışmalarında TRB2 bölgesinde 66 işletme ve 132 yönetici üzerinde yaptıkları incelemede, stratejik yönetim kavramlarının uygulandığı işletmelerin inovasyon performanslarının daha fazla olduğunu tespit etmişlerdir.

Uluslararası alan yazın incelendiğinde ise Bonnici ve Paroutis (2013) çalışmalarında stratejik yönetim ve inovasyonun kesişim süreçlerini incelemişler, stratejik yönetim süreçlerinin inovasyon süreçlerine olumlu katkı sağlayabileceğini savunmuşlardır. Stratejik yönetim süreçlerini uygulayan ve bu süreçleri işletme kültürüne yerleştiren işletmelerin inovasyon süreçlerinde ve verimlilikte daha başarılı olacaklarını savunmuşlardır. Drejer (2006) çalışmasında piyasa koşullarının 1960’lı yıllara göre 
çok daha hareketli olduğunu ve işletmelerin bu yönde tedbir alması gerektiğini savunmuş, stratejik yönetimin ve inovatif düşünce yapısının işletmelerce uygulanması gerektiğini öne sürmüştür. Stratejik yönetim ve inovasyon anlayışının birbirinden ayrı düşünelemeyeceğini belirten Drejer, inovatif düşünce yapısının stratejik yönetimin gerekliliklerinin yerine getirilmesiyle gerçekleşebileceğini öne sürmüştür (3). Rothwell ve Gardiner (1989) çalışmalarında etkili inovasyon stratejilerinin üretim alanında faaliyet gösteren işletmelerin ürünlerini müşteriye daha kısa sürede ulaştırdığını ve bunun sonucu olarak daha kısa sürede daha fazla ürün satma durumunun ortaya çıktığını belirtmişler, ürünlerin inovasyonunun ve üretim süreçlerinin hızlanmasının üst yöneticilerin stratejik yaklaşımına bağlı olduğunu öne sürmüşlerdir.

Keupp, Palmie ve Gassman (2012) çalışmalarında inovasyon süreçlerinin artık işletmeler için bir gereklilik olarak kabul edildiğini, inovasyon süreçleriyle birlikte stratejik yönetim kararları uygulamanın genel kabul gördüğünü ancak inovasyonun stratejik yönetimi alanında henüz teorik boşlukların ve bazı bilgi tutarsızlıklarının olduğunu belirtmişler bundan dolayı 1990'dan 2010'a kadar inovasyonun stratejik yönetimi hakkında yayınlanan 342 yazıyı çalışmalarında nitel metodlarla incelemişlerdir. Genel olarak işletmelerin yönetim süreçleriyle, hizmet süreçleriyle ve organizasyon yapılarıyla inovasyon arasındaki bağın incelendiği çalışmaların az olduğunu tespit etmişler ve teorik boşlukların bu alanlara yönelecek çalışmalarla doldurulabileceğini belirtmişlerdir.

Konuyla ilgili ulusal ve ulusararası alan yazın incelendiğinde çalışmaların inovasyonun günümüzün getirdiği rekabet koşullarında işletmeler için bir gereklilik olduğunu, işletmelerin inovasyon geliştirebilmesi için ise stratejik yönetimin bir gereklilik olduğunu belirttiği görülmektedir. Ancak işletmeler üzerinde stratejik yönetim ve inovasyon arasındaki ilişkinin incelendiği alan araştırmaları ulusal ve uluslararası alan yazında az sayıdadır. Konunun önemine vurgu yapan Keupp vd. (2012) çalışmalarında konuyla ilgili teorik boşlukların stratejik yönetimle bağlantılı süreçlerin inovasyonla bağlantısının araştırılması sonucunda doldurulabileceğini belirtmişlerdir. Çalışmanın bu bakımdan alan yazına katkısı olabileceği düşünülmektedir. Çalışmanın Türkiye'nin ikinci büyük kentinde yapılmış olması ise KOBİ sahiplerinin ne derece stratejik yönetim ve inovasyon anlayışına sahip olduğunu göstermesi bakımından önem arz etmektedir. Yapılan araştırmada işletme yöneticilerinin genel stratejik yönetim algılarının orta düzeyde olduğu ve buna paralel olarak yöneticilerin genel inovasyon süreçlerine yönelik algılarının da orta düzeyde olduğu tespit edilmiştir. Aradaki doğru orantı stratejik yönetim ve inovasyon ilişkisini kanıtlar niteliktedir. Yine yöneticilerin stratejik yönetim algıları ile inovasyon süreçleri arasında ne düzeyde ilişkiler bulunduğu sonucuna ulaşmak için yapılan pearson kolerasyon katsayısı hesaplamasında ise genel olarak stratejik yönetim algıları ile inovasyon süreçleri arasında pozitif yönde, orta ve yüksek düzeyde ilişkiler olduğu sonucuna ulaşılmıştır. Ayrıca kurulan yapısal eşitlik modeliyle yapılan analizlerde yöneticilerin inovasyon süreçleri geliştikçe stratejik yönetim algısının da geliştiği sonucuna ulaşılmıştır. Genel çerçeveden bakıldığında stratejik yönetim ve inovasyon arasındaki ilişkinin bariz olarak görüldüğü ve doğru orantılı bir şekilde ilişki içinde oldukları tespit edilmiştir. $\mathrm{Bu}$ sonuçlar alan yazında yapılan çalışmaları ve öne sürülen hipotezleri doğrular niteliktedirler. İnovasyonu etkili bir şekilde oluşturmak ve uygulamak için en önemli başarı faktörleri stratejik olmak ve liderlik yürütebilmektir. Aynı şekilde etkin bir strateji yürütemeyen işletmelerin inovasyon yönetiminin gerektirdiği aşamaları gerçekleştirmesi mümkün olmamaktadır (Cormican ve O'sullgvan, 2004).

İnovasyonun ortaya çıkma sürecine baktığımızda geleceğe dönük değişimleri, tüketici davranış ve tutumlarını ve gelişen teknolojiyi izleyerek yeni stratejiler ortaya koyan, yani bir bakıma dış çevreyi iyi bir şekilde gözlemleyip bunun analizlerini yapabilen işletmelerin inovasyon konusunda daha ileri bir noktada olduğu görülmekte ve strateji geliştirmede izlenen yol ve yöntemlerin, işletmelerin inovasyon yetenek ve algıları üzerinde daha efektif olabileceği fikri ortaya çıkmaktadır (Pınar, Kamaşak ve Bulutlar,2009).

Bu bakımdan günümüzün gelişen dünyasında büyümek, gelişmek ve hayatta kalabilmek için küçük ve orta büyüklükteki işletmelerin stratejik yönetim anlayışını ve bunun bir sonucu ve aynı zamanda nedeni olan inovasyonu yönetimlerinin bir parçası haline getirmeleri gerekmektedir. $\mathrm{Bu}$ 
doğrultuda küçük ve orta büyüklükteki işletmeler hızla değişen dış çevre koşullarına daha çabuk ve etkin uyum sağlayıp, inovasyon süreçlerini başarıyla yürüteceklerdir.

Küçük ve orta büyüklükteki işletmelerin dünya ve ülkemiz ekonomisindeki yerlerine bakıldığında ise bu işletmelerin büyümesi ve gelişmesi daha çok üretim ve istihdam sağlayacağından konu ayrıca önem arz etmektedir. Ülkemizin barındırdığı genç nüfus dikkate alınırsa, girişimcilik ruhunun yaygınlaştırılması, küçük ve orta büyüklükteki işletmelerde stratejik yönetim ve inovasyon bilincinin oluşturulması dünya ekonomisinde daha fazla pay oranına sahip olmamıza, ülkemizde istihdam ve üretimin arttırılmasına katkı sağlayabilecektir.

İşletmelerin stratejik kararlarının geleceklerini etkilediğinden, doğru analizler 1şı̆̆ında bu kararların alınması gerekmektedir. Bu çalışmada stratejik kararlar ile inovasyon arasındaki ilişkiler ele alınmıştır. Başka çalışmalarda teknolojik gelişmeler, değişen müşteri davranışları, sektörel gelişmeler, sürdürülebilir rekabet avantajları gibi değişkenler ile stratejik kararlar arasındaki ilişkilerin incelenebileceği önerilmektedir.

Bilimsel çalışmaların, işletmelerin günlük problemleri ve sürdürülebilir rekabet avantajı sağlamalarını sağlayacak konular üzerine yoğunlaşması teori ile pratiği birleştirecek olması açısından çok önemlidir. Bu nedenle yine araştırmacılara işletmelerin stratejik karar almalarına yardımcı olacak güncel konuları ele alarak ilgili işletmeler ile sonuçları paylaşmaları önerilebilir. 


\section{Kaynaklar}

Akdemir, B. (2010). Stratejik yol haritası uygulamasının stratejik yönetim bilincine etkisinin belirlenmesine yönelik bir araştırma. Journal of New World Sciences Academy, 5(4) 320-341.

Akgül, A. ve Çevik, O. (2003). İstatistiksel analiz teknikleri (SPSS' te işletme yönetimi uygulamalart), Ankara: Emek Ofset.

Aktaş, E. (2018). İnovasyon yönetimi ve işletmelerde inovasyon yönetimine yönelik bir araştırma. Yüksek Lisans Tezi. Okan Üniversitesi, İstanbul.

Athapaththu, H. H. (2016). An overview of strategic management: an analysis of the concept sand the importance of strategic management. International Journal of Scientific and Research Publications, 6(2), 124-133.

Baykal, T. (2018). Örgütlerde etkinlik ve etkililik için stratejik yönetim ve stratejik planlama. Social Sciences Research Journal, 7(2), 151-160.

Bonnici, T. S. and Paroutis, S. (2013). Developing a dominant logic of strategic innovation. Management Research Review, 36(10), 924-938.

Büyüköztürk, Ş., Çakmak, E., Akgün, Ö., Karadeniz, S. ve Demirel, F. (2010). Bilimsel araştırma yöntemleri. Ankara: PegemA Akademi.

Cormican, K. and O'sullgvan, D.(2004). Auditing best practice for effective product innovation management. Technovation, 24(10), 819-829.

Creswell, J. W. (2009). Qualitative inquiry \& research design: Choosing among five approaches (3. Bask1). USA: SAGE Publications.

Çavuş, M. F. (2005). Aile işletmelerinde stratejik yönetim. Çukurova Üniversitesi Sosyal Bilimler Enstitüsü Dergisi, 14(2), 152-166.

Çokluk, Ö., Şekercioğlu, G. ve Büyüköztürk, Ş. (2010). Sosyal bilimler için çok değişkenli istatistik SPSS ve LISREL uygulamalart. Ankara: Pegem Yayıncılık.

Demir, Ö. ve Sezgin, E. E. (2016). Kobilerde stratejik yönetim anlayışına inovasyon perspektifinden bakış. Siirt Üniversitesi İktisadi ve İdari Bilimler Fakültesi İktisadi Yenilik Dergisi, 4(1), 16-31.

Demir, D. (2017). Stratejik yönetim ve marka yönetimi arasındaki ilişkinin incelenmesi: bir sektör uygulaması (Tekstil Hazır Giyim). Yüksek Lisans Tezi. Arel Üniversitesi, İstanbul.

Drejer, A. (2006). Strategic innovation: a new perspective on strategic management. Handbook of Business Strategy, 7(1), 143-147.

Dursun, Ö. O. (2017). İnovasyon üzerine kavramsal bir inceleme. International Journal of Management and Administration, 1(1), 12-17.

Emeksizoğlu, B. (2008). Imalat sektöründe inovasyon, Türkiye'de inovasyona yönelik engeller, kaynaklar ve teşvikler. Yüksek Lisans Tezi. İstanbul Teknik Üniversitesi, İstanbul.

Esmaeili, N. (2015). Strategic Management and its application in modern organizations. International Journal of Organizational Leadership, 4, 118-126.

Eşki, H. (2009). Stratejik yönetim ve örgüt kültürü; ilişkisel bir analiz. Dumlupınar Üniversitesi Sosyal Bilimler Dergisi, 24, 164-171. 
Günay, Ö. (2007). KOBI'lerde yenilik türlerinin analizi ve yenilik engellerinin belirlenmesine yönelik bir araştırma. Yüksek Lisans Tezi. İstanbul Üniversitesi, İstanbul.

Hancıoğlu, Y. ve Yeşilaydın, G. (2016). Stratejik yönetimde yeni bir rekabet yaklaşımı: Stratejik İnovasyon. Uluslararası Yönetim Iktisat ve İşletme Dergisi, 12(29), 105-124.

Kalay, F., Tuncer, C.O., Kızıldere, C. ve Kalay, H.A. (2015). Stratejik inovasyon yönetimi uygulamalarının firma inovasyon performansı üzerindeki etkileri. Bilgi Ekonomisi ve Yönetimi Dergisi, 10(2),7-77.

Karsavuran, S. (2013). Stratejik değerlendirme ve kontrol: dengeli puan kartı'nın sağlık hizmetlerinde kullanımı. Hacettepe Üniversitesi Să̆lık İdaresi Dergisi, 16(2), 69-90.

Keskin, S. (2018). Girişimcilik ve inovasyon arasındaki ilişki. Gazi Üniversitesi Sosyal Bilimler Dergisi, 5(13), 186-193.

Keupp, M. M., Palmié, M. and Gassmann, O. (2011). The strategic management of innovation: A systematic review and paths for future research. International Journal of Management Reviews, 14, 367-390.

Kılc1, H. (2013). Küçük ve orta ölçekli işletmelerde stratejik yönetim uygulamaları: Tokat ili imalat kobileri üzerinde bir çalışma. Yüksek Lisans Tezi. Gaziosmanpaşa Üniversitesi, Tokat.

Kılıç, R. ve Keklik, B.(2012). Kobi'lerde genel firma özelliklerinin inovasyon uygulamalarına etkisi: Balıkesir ilinde bir araştırma. Erciyes Üniversitesi İktisadi ve İdari Bilimler Fakültesi Dergisi, 39, 93-118.

Organisation for Economic Co-operation and Development. (2005). www.oecd.org. https://stats.oecd.org/glossary/detail.asp?ID=6870 adresinden 20.12.2018 tarihinde edinilmiştir.

Organisation for Economic Co-operation and Development. (2005). www.oecd.org. https://www.oecd.org/site/innovationstrategy/defininginnovation.htm adresinden 14.11.2018 tarihinde edinilmiştir.

Organisation for Economic Co-operation and Development. (2005). www.oecd.org. https://www.oecd.org/site/innovationstrategy/defininginnovation.htm adresinden 21.09.2018 tarihinde edinilmiştir.

Organisation for Economic Co-operation and Development. (2005). www.oecd.org. https://www.oecd.org/site/innovationstrategy/defininginnovation.htm adresinden 02.01.2019, tarihinde edinilmiştir.

Organisation for Economic Co-operation and Development. (2005). www.oecd.org. https://stats.oecd.org/glossary/detail.asp?ID=6871 adresinden 03.01.2019 tarihinde edinilmiştir.

Organisation for Economic Co-operation and Development. (2005). www.oecd.org. https://www.oecd.org/site/innovationstrategy/defininginnovation.htm adresinden 01.07.2019 tarihinde edinilmiştir.

Organisation for Economic Co-operation and Development. (2005). www.oecd.org. https://stats.oecd.org/glossary/detail.asp?ID=6873 adresinden 01.10 .2019 tarihinde edinilmiştir. 
Organisation for Economic Co-operation and Development. (2005). www.oecd.org. https://www.oecd.org/site/innovationstrategy/defininginnovation.htm adresinden 24.01.2019 tarihinde edinilmiştir.

Öztokmak, Z. (2018). Yeni tüketim kültürü ve inovasyon çerçevesinde Konya ilinde bulunan üniversite ögrencilerinin fast food tüketim alışkanlıklarının incelenmesi. Yüksek Lisans Tezi. KTO Karatay Üniversitesi, Konya.

Peker, A. E. ve Boyraz, A. (2017). Stratejik yönetim kavramına teorik bir yaklaşım. Fırat Üniversitesi İktisadi ve İIBF Uluslararası İktisadi ve İdari Bilimler Fakültesi, 1(2), 67-92.

Persaud, N.,Woodhouse, M. and Scriven, M. (2016 ). Enhancing the strategic management process through the use of professional evaluation methods and the logic of evaluation. Journal of Multi Diciplinary Evaluation, 1-11.

Pınar, İ., Kamaşak, R. ve Bulutlar, F. (2009). Strateji geliştirme süreçlerinin yenilikçilik üzerinde etkisi. 21-23 Mayls 17. Ulusal Yönetim ve Organizasyon Kongresi, (ss. 399-404). Eskişehir.

Rothwell, R. and Gardiner, P. (1989). The strategic management of re-innovation. R\&D Management, 19(2), 147-160.

Sat1, Z. E.ve Işı, Ö. (2011). İnovasyon ve stratejik yönetim sinerjisi: Stratejik inovasyon. Celal Bayar Üniversitesi Sosyal Bilimler Dergisi, 9(2), 538-559.

Tabachnic, B. and Fidell, L. (2007). Using multi variale statistics. Cambridge: Harper\&Row.

Turengül, M. (2007). Stratejik yönetim ve kriz dönemlerinde önemi. Dumlupınar Üniversitesi Fen Bilimleri Enstitüsü Dergisi, 14, 65-72.

Türk, M. ve Kara, E. (2017). Konaklama işletmelerinde stratejik yönetim süreci: Yöneticiler üzerine bir araştırma. Uluslararası Toplum Araştırmaları Dergisi, 7(13), 552-574.

Utterback, J. M. and Abernathy, W. J. (1975). A dynamic model of processand product innovation. The International Journal of Management Science, 3(6), 639-656.

Van Veen-Dirks, P. and Wijn, M. (2002). Strategic control: meshing critical success factors with the balanced scorecard. Long Range Planning, 35, 407-427. 


\section{Extended Abstract}

\section{Introduction}

In an intensive competition, companies need to follow innovations and determine strategies related tot he future. Strategic management decisions of enterprises have a great importance to achieve the seinnovation sand changes. Strategic decisions are important decisions which is made by senior management. Strategic decisions are the decisions made that shape the future of the company in many areas.Due to analysing the inside and the outside environment as regarding to the vision of the company, determining a strategy is a hard process. Many factors should be considered while determining strategies. One of them is innovation.

Although the innovation and strategic management concepts are entirely different, there is a strong relationship between them. Because, creating a successful value through innovation is directly related to the objectives of the enterprises, the strategies they have determined for their objectives, the external environmental analys is they have made, the irmanagement structures, the resources they have allocated for investment sand their actions for their strageties determined.

Strategic management and innovation concepts are getting more important especially for small and medium-sized enterprises because of the increasing number of small and medium-sized enterprises day by day in the world and in our country and already $99.8 \%$ of the enterprises in our country are small and medium-sized enterprises. Small and medium-sized enterprises have a vital importance for the economy of our country because of their contribution to GNP, employment and creating value addition. In order to survive and grow in competitive markets in today's changing world, the companies need to have strategic management awareness and successfully apply innovation processes.

These concepts have become a necessity for SMEs which have a great importance for the world and our country's economy. Since the number of studies related to the determination of relationship between strategic management and innovation in SMEs is un sufficient, the study is also important. In this study, in itially strategic management and innovation concepts are emphasized and then the analys is results of the data collected throughth study are given. Some suggestions were made through the results of the analysis. It is thought that the study will set light on the studies about this concepts and SMEs.

\section{Method}

The aim of this study is to examine the impact of strategic management on innovation processes. In this direction, the research was designed in the relational screening model which is one of the quantitative research methods. In the relational screening model, correlations among the thoughts, attitudes or tendencies of a group are calculated and relations are determined; accordingly, the research is also calledas correlational research.

Within the scope of the research, a total of 300 managers in 35 different sectors were interviewed which are operating in areas such as paint materials, glass, cement, furniture and automotive. Within the scope of the research, managers of work places from different sectors werei ncluded into the study by using maximum diversity sampling method.

\section{Result}

In this study, it was determined that the general strategic management perceptions of the company managers are at the middle level and the perceptions of the managers about the general innovation processes are at the middle level as well. Straight proportion determined, proves the relationship between strategic management and innovation. In addition, in the calculation of the Pearson correlation coefficient, which was used in order to determine the level of relationship between strategic 
management perceptions and innovation processes, it was determined that there were medium and high level relationships between strategic management perceptions and innovation processes in positive direction.

In addition, in the analyzes conducted with the structurale quality model, it was fixed that the strategic management perception developed as the innovation processes of the managers improved. From point of a general view, it has been seen that the relation between strategic management and innovation is obvious and they are in direct proportion.

\section{Discussion and Conclusion}

In this respect, in order to grow, develop and survive in today's developing world, small and medium-sized enterprises need to make as a part of their management strategic management understanding and innovation which is a result and reason of this, as well.In this direction, small and medium-sized enterprises will be able to adapt to the changing external environmental conditions more quickly and effectively and carry out their innovation processes successfully.

Considering the importance of strategic management and SMEs, this study will contribute to the literature related to the research findings. Increasing the studies in this field and sharing the results with the enterprises will contribute to the sectoral development. Such studies will contribute to the solution of sectoral problems in the light of scientific data.

Since the strategic decisions of enterprises affect their future, these decisions should be taken in the light of true analyzes. In this study, the relationships between strategic decisions and innovation are discussed. In other studies, it is suggested that the relationships between variables such as technological developments, changing customer behaviors, sectoral developments, sustainable competitive advantages and strategic decisions can be examined.

Focusing the instutions on the issues that will enable them to solve daily problems and to get sustainable competitive advantage is very important in terms of combining theory and practice. For this reason, researchers may be advised to share the results with the relevant enterprises by handling the current issues that will help the enterprises to make strategic decisions. 